\title{
Narrativas de mujeres quebram Coco Babaçu em el sudeste de Pará
}

\author{
Narrativas de mulheres quebradeiras de Coco Babaçu no sudeste de Pará \\ Narratives of broken women of Coco Babaçu in southeast Pará
}

\author{
Maria de los Angeles Arias Guevara 1 \\ Marlenis Tamanini2
}

\begin{abstract}
RESUMEN
Este artículo analiza narrativas que revelan y resignifican la experiencia de mujeres que quebran Coco Babaçu en sudeste de Pará, mostrando que su agencia como sujetos políticos es construida en un contexto de conflictos socioambientales y en defensa de su territorio simbólico
\end{abstract}

PALABRAS CLAVES: Narrativas. Experiencia. Agencia. Conflictos Sócioambientales. Territorio Simbólico.

\section{RESUMO}

Este artigo analisa narrativas que revelam e ressignificam a experiência de mulheres que quebram Coco Babaçu no sudeste do Pará, mostrando que sua agencia como sujeitos políticos é construída em um contexto de conflitos socioambientais e em defesa de seu território simbólico.

PALAVRAS-CHAVE: Narrativas. Experiencia. Agencia. Conflitos Sócioambientales. Território Simbólico.

\begin{abstract}
This article analyzes narratives that reveal and resignify the experience of women who break Coco Babaçu in southeast Pará, showing that their agency as political subjects is built in a context of socio-environmental conflicts and in defense of their symbolic territory.
\end{abstract}

KEYWORDS: Narratives. Experience. Agency. Socio-environmental conflicts. Symbolic Territory.

\footnotetext{
1 Professora visitante en la Universidad Federal de Lavras-MG, Brasil. Dra. em Ciências filosóficas y Maestra em Sociologia por la Universidad de La Habana, Pos-doctora por Colegio de Pos-graduados de México, por Programa en Dinâmicas Socio Territoriais e Sociedade na Amazônia da UNIFESSPA y por Programa Sociologia da UFPR. Professora Titular por la Universidade de Holguín, Cuba. Investiga sobre desarrollo rural, ruralidades, conflitos socio ambientales, género, agroecologia y economía solidaria, colocando el énfasis em el trabajo y cuidado, en la experiencia y agencia de las mulheres rurais. E-mail: ariasguevara2011@gmail.com.
}

2 Universidade Federal do Paraná. Decorado Interdisciplinar por la UFSC. Posdoctorado por la Universidade de Barcelona. Coordenadora do Núcleo de Estudos de Gênero. Cocoordenadora do Programa de Pós-Graduação e Sociologia. E-mail: tamaniniufpr@gmail.com. 


\section{Introducción}

Estudiar la experiencia y la agencia que contienen las narrativas de las mujeres quebradoras de Coco Babaçu en el sudeste del Pará, es movilizar la dimensión cultural del uso del territorio3, que refiere a un proceso de apropiación a partir de los valores y saberes históricamente acumulados en la memoria colectiva. Se trata de un proceso que se actualiza en la dinámica de las prácticas cotidianas como plantar, cosechar, recolectar, producir artesanías, y medicinas, transformar alimentos, realizar las prácticas religiosas y pedagógicas, entre otras. Asimismo, sugiere, tener presente las representaciones simbólicas, los sentidos prácticos colocados en la vida colectiva, sea para mantener vivas las palmeiras que producen el Coco Babaçu o, sea para obtener productos para los rituales de cura y protección. El valor atribuido a la naturaleza, en consecuencia, envuelve necesidades y cuidados, pues en ella están los bienes necesarios para la vida y, por tanto, precisan de su preservación.

Esta perspectiva nos moviliza, hacia el uso de la dimensión ambiental y política del territorio, en tanto actores sociales, como las mujeres, luchan y resisten a la hegemonía del modelo neo-extractivista, ganadero y/o maderero depredador de los bosques; así como a las relaciones de poder desiguales a escala familiar e local que limita la gestión ambiental de espacios de los que depende su sobrevivencia. Significa entonces que inscribimos - como agencias en la lucha por el territorio - a las experiencias de las mujeres en la defensa de, por ejemplo, las palmeras que hacen las mujeres quebradoras de coco babaçu (Orbignya phalerata) ${ }_{4}$

\footnotetext{
${ }^{3}$ Desde el punto de vista teórico-conceptual estamos entendiendo el territorio como un campo social de conflictos por el poder que se expresan, en el caso del sudeste del Pará, como procesos continuos de lucha por el acceso, apropiación, desapropiación y reapropiación del espacio.

${ }_{4} \mathrm{El}$ coco babaçu es el fruto de una especie de palmera nativa del norte, nordeste y centro oeste del Brasil (Orbignya phalerata) cuyo aprovechamiento es integral desde las pencas hasta su fruto. Un análisis detallado puede encontrarse en: "Uma palmeira em muitos 
Los conflictos socio-ambientales en el sudeste del Pará están siendo comprendidos en este estudio como aquellos que se generan por los modelos extractivistas en suelo rural - por el agua, el suelo, los bienes de los bosques que envuelven en sí mismos las resistencias de los actores sociales contra el proceso de destrucción de sus territorios y su modo de vida.

Las prácticas de la ganadería extensiva, del agronegocio, la minería, la explotación forestal, las grandes obras hidroeléctricas y de infraestructura vial, tienen consecuencias desbastadoras para la biodiversidad en su totalidad. En esta diversidad de la vida afectada están incluidos los pueblos tradicionales indígenas y campesinos, mediante desplazamientos forzados, destrucción de sus modos y medios de vida rural, contaminación de sus fuentes de agua y el aire que respiran. Estos procesos no se dan sin que los actores sociales, entre ellos las mujeres organizadas, expresen sus resistencias en un campo de correlación de fuerzas desiguales.

Los conflictos y, con ellos, la violencia, crecen en la misma medida en que la tierra, el agua y otras riquezas del subsuelo son valoradas por capital trasnacional. Entonces, un territorio como el que comprende el sudeste del Pará resulta estratégico en la geopolítica mundial, y se convierte en caldo de cultivo para la reconcentración de la tierra en función de intereses globales, con la anuencia del Estado y las elites locales. Estos procesos son operados a la sombra del poder, cuyos ejemplos se encuentran siempre en las narrativas de las mujeres, revelando en sus cuestionamientos las desigualdades de género en las relaciones con los bienes de la naturaleza, en un contexto en que cercenan sus derechos al territorio.

La metodología de colecta de la información empírica emergió de la postura etnográfica asumida que valoriza el contacto directo con la cotidianidad vivida por las Mujeres Quebradoras de Coco Babaçu, el diálogo a través del cual ellas construyen una narrativa sobre sus trayectorias de vida hasta el hoy y el aquí. La Metodología se apoya, además, en la recuperación de sus voces contenidas en los relatorios de los mapeamientos participativos:

termos: a terminologia da cultura agroextrativista, industrial e comercial do coco babaçu" de Josete Marinho (2008). 
herramienta metodológica en los que las mujeres mapean sus territorios simbólicos como espacios de conflitos socioambientales. Todo ello permitió la construcción de un conocimiento que brota de un tiempo compartido, de valorización de saberes anclados en la experiencia de las mujeres, vigilando lo específico que puede informar una lectura interseccional de género en sus propios espacios de vida. Todo un proceso que articula largas conversaciones que desencadenan palabras que luego se tejen y encadenan para que sus voces no estuvieran ausentes en el texto que como autoras debíamos construir.

La perspectiva epistémica que guía el trabajo en lo fundamental, se apoya los Feminismos del Sur, que nos permiten valorizar los saberes anclados en la experiencia de las mujeres, no como categoria homogénea, sino desde la intersepcionalidad que inscriben en sus cuerpos las condiciones de clase, de étnia, de raza, de generación, de território, entre otros. Construir conocimientos situados con y no conocimiento sobre.

Así el objetivo pretendido fue: comprender a través de sus narrativas la experiencia y agencia de mujeres quebradoras de Coco Babaçu en un territorio como sudeste de Pará, donde los conflictos socio-ambientales las confrontan a los intereses del capitalismo global bajo el amparo de relaciones de poder locales.

\section{Los babuçuais como territorio simbólico donde se construye la agencia}

En el estado de Pará, el contexto específico de las luchas de las mujeres de comunidades tradicionales que se identifican como Quebradoras de Coco Babaçu abarca espacios rurales ubicados en el valle del río Tocantins cuya área de babuçuaiss comprende unas 290,000 hectáreas de tierra, en lo fundamental de los municipios San Domingo do Uruguaia, Palestina, Brejo Grande, y San Juan do Uruguaia (MIQCB, 2013). La conocida "Región Ecológica dos Babaçuais 6 " abarca un área aproximada de 18,5 millones de

\footnotetext{
5 A lo largo del texto se usa babuçuais, nombre que las mujeres dan a la palmera y no su nombre científico (Orbignya phalerata), así como el plural e portugués: babuçuais.

6 Denominación utilizada por el Movimiento Interestadual de Quebradeiras de Coco Babaçu (MIQCB) para identificar espacios donde trabajan las mujeres que lo integran como comunidades tradicionais, sin obedecer a términos geográficos.
} 
hectáreas pertenecientes a los estados de Maranhão, Pará, Piauí, Tocantins, Goiás e Mato Grosso (ALMEIDA, 2005).

Las mujeres que por generaciones han sustentado a su familia de la renta que emerge del extractivismo del coco babaçu, son mujeres en condición de pobreza, cuerpos negros en más de un 90\%, subescolarizadas, pertenecientes a varias generaciones, marcadas por la violencia patriarcal del colonialismo interno que como modo de dominación "atraviesa la sociabilidad, el espacio público y el espacio privado, la cultura, las mentalidades y las subjetividades" (SANTOS, 2011, p. 24) y por la expansión del capitalismo trasnacional encarnado en el agronegocio y la explotación mineral que les priva de una fuente de alimento familiar y de renta: los cocos babaçu.

La devastación de los babuçuais para el desarrollo de la pecuaria, sea por el corte o por el envenenamiento de las palmeras amenaza la principal fuente de sobrevivência de las quebradoras. Otra situación más reciente es el arrendamiento de los babuçuais para la extracción del coco entero para fabricar el carbón que alimenta el parque industrial de la ciudad de Marabá, y de otras industrias ubicadas en el estado de Marañao. Las llamadas Ferro gusas demandan del carbón para derretir el hierro en sus hornos. Teniendo en cuenta los límites que impone la legislación ambiental para dar continuidad a la desvastación de los bosques amazónicos, las empresas convierten al coco en materia prima estratégica para alimentar sus siderurgias; cuestión que tensiona la existencia de una cultura tradicional que organizó formas específicas de relacionarse con la naturaleza, asimismo, afecta la reproducción social, cultural y física de las mujeres quebradoras del coco babaçu.

Como en otros estados del norte-nordeste de Brasil, en el sudeste del Pará7, los babuçuais no son sólo un elemento esencial del paisaje, ellos conforman un circuito económico de subsistencia, que puede llegar hasta el $80 \%$ de la renta familiar, cuyo trabajo es realizado por mujeres que se identifican como quebradoras de coco babaçu. Los babuçuais marcan la

7 El Sudeste de Pará está conformado por 14 municipios, abarca um espacio de aproximadamente, $54.469 \mathrm{~km}^{2}$, con uma población de más de 617 mil habitantes. 
historia, los rituales, las subjetividades, la experiencia y agencia de estas mujeres, que generación tras generación relacionan sus prácticas sociales con el Coco Babaçu. Los babaçuais pueden ser considerados territorios simbolicamente construidos, a partir de prácticas sociales que conforman contextos particulares de relación entre las mujeres y el ecosistema que las sustenta y da sentido a su modo de vida, espacios de enunciación a partir de los cuales su experiencia y agencia es narrada.

Estos territorios, constituyen espacios de confrontación entre modelos económicos, en el que las mujeres son las protagonistas que dilatan el presente, por que defienden una tradición cultural que viene del pasado, para asegurar su futuro. Los espacios de vida y trabajo de las mujeres quebradoras de coco babaçu, de otros pueblos tradicionales, como riberiños, indígenas, quilombolas, y de poblaciones campesinas, son el blanco en la estrategia global que sigue el capital trasnacionalizado en el sudeste del Pará, dirigida a la mercantilización de los bienes comunes de la naturaleza a la reprimarización de la economía y al despojo de las poblaciones locales, lo que ha sido denominado "acumulación por desposesión” (HARVEY, 2005). Proceso que implica además, la implementación de mecanismos para dar legalidad al despojo, que van desde la creación de áreas de reserva ambiental donde se desautoriza el uso por los pueblos indígena o tradicionales, concesiones a empresas trasnacionales, aprobación de políticas e instrumentos jurídicos de apoyo, paralización de la reforma agraria, uso de la violencia estatal, judialización y criminalización de los movimientos sociales en resistencia, entre otras, orientadas todas ellas, a concretar el despojo.

Como acto de desterritorialización, este proceso atraviesa los cuerpos y las subjetividades, trastoca identidades, destruye los modos y fuentes de vida así como las maneras históricas de relacionamiento de las poblaciones tradicionales con la naturaleza. Se ha comprobado que la minería en el sudeste del Pará afecta la vida de más de un millón de personas en 26 municipios, provoca muertes y perjudica la sociabilidad de las comunidades (COELHO, 2015, p. 50), contamina el aire, el agua y consume vidas de hombres y mujeres consideradas descartables a través de los mecanismos de 
terciarización del trabajo que no responsabiliza a la Empresa Vale S.A. por las enfermedades que causa en sus trabajadores/as, simplemente los descarta. El abundante mercado de trabajo permite su rápida sustitución. Otra cuestión, está en el control que se ejerce sobre poblaciones enteras considerado una especie de biopoders, que articula alianzas con el latifundio, el poder policial y judicial.

La lógica depredadora de la territorialización del capital acciona variables de una visión en la que lo humano y no humano son considerados objeto de dominación, se sacrifican los mundos y modos de vida tradicionales en el relacionamiento con la naturaleza y la naturaleza misma es vista como espacio mercantilizado, la vida es subordinada a la obtención de lucro y este sólo se logra a través de la violencia. Baste citar, siguiendo a Maria Pinassi y Raimundo Gomes Da Cruz (2015) que luego de cuatro décadas de explotación mineral, el resultado del llamado "desarrollo" de la amazonia oriental no podría ser peor:

más de un millón de hectáreas de castañales destruidos, (...) floresta quemada para siembra de pasto, rios y nacientes contaminados. Centenas de productores rurales, indígenas, representantes de movimentos y de la iglesia amenazados y asesinados (PINASSI y GOMES, 2015 p.39).

Una economía basada en valores del patriarcado y del mercado capitalista, "pasa por alto el valor económico de dos economías vitales que son necesarias para la supervivencia humana y ecológica: la economía de la naturaleza y la economía del sustento" (SHIVA y MIES, 2013, p.19). Siendo los babuçais un regalo de la naturaleza, no pertenecen entonces al propietario de la tierra, ni al capital trasnacionalizado, son un espacio de simbiosis entre los pueblos tradicionales y la natureza, entre las mujeres que quiebran el coco y sus palmeras. En la actualidad son espacios de lucha por los derechos

\footnotetext{
8 El concepto biopoder elaborado por Michel Foucault en la década de los 70, nos auxilia en la comprensión del comportamento de la mineradora Vales S. A, entendido ese concepto en el sentido del comportamiento control y dominación de los cuerpos em el sudeste del Pará.
} 
historicamente negados, reivindicaciones cimentadas en la experiencia y expresadas en su agencia.

La apropiación del territorio por el capital se convierte así en una cuestión feminista, en tanto, nos ayuda a comprender sus efecto en la opresión de las mujeres y los vínculos conceptuales entre la dominación de ellas y la dominación de la naturaleza, cuestión esta develada por el Ecofeminismo cuando analiza el vínculo histórico entre la violencia contra las mujeres y la violencia contra la naturaleza.

la violación de la Tierra y la violación de las mujeres están estrechamente relacionadas: tanto desde el punto de vista metafórico, al determinar cosmovisiones, como material, al determinar la vida cotidiana de las mujeres. La mayor vulnerabilidad económica de las mujeres las vuelve más inermes ante toda forma de violencia, incluida la agresión sexual (SHIVA y MIES, 2013, p. 20).

Preguntarnos ¿cómo se entrecruza esta realidad con las trayectorias de vida que son narradas por las mujeres quebradoras de Coco Babaçu? ¿Y Por qué es esta una cuestión feminista? Ello nos condujo al análisis de cómo esas desigualdades se iscriben en sus cuerpos. Una realidad que inter-relaciona varias formas de poder jerárquico entre el capitalismo, el colonialismo interno y el heteropatriarcado, contenida en sus narrativas a través de las cuales comprendemos sus experiencias y agencias.

\section{Diálogos con los estudios realizados, la teoría y la metodologia}

El conocimiento del contexto, la interacción con el campo y las necesidades teóricas que de el irían emergiendo nos condujo a la búsqueda de estudios realizados sobre las mujeres quebradoras de Coco Babaçu, lo que significó la inmersión en una vasta bibliografía que recoge pesquisas desde diferentes disciplinas y perspectivas teóricas, casi todas realizadas desde una visión de corte estructuralista, buscando las lógicas económicas y estructurales que condicionan acciones y estratégias del movimento social de 
las quebradoras de Coco Babaçu en general, en una temporalidad que remite siempre a sus orígenes hasta el hoy; y en un espacio de análisis más regional o, el caso particular del estado de Maranhão, como referencia de las luchas y sede de la organización, sin hacer énfasis en estudios micro. (ALMEIDA, 2005, MARINHO,2008; MEDEIROS DA SILVA, 2008)

Si los autores mencionados no enfatizan en la diversidad de experiencias, de sentidos cotidianos que las acciones y prácticas le imprimen a cada espacio, desde el cruce de sus identidades como quebradoras de coco, con otras que tienen que ver con su etnicidad, edad, religiosidad, vínculos, relaciones familiares, y associativismo, son significativos aquellos que atienden espacios selecionados en Maranhão y Tocantins y desde una postura etnográfica examinan los caminos recorridos por las mujeres en defensa de su identidad como extractivistas, su organización y cuestionamiento de las normas excluyentes, sus identidades de género desde lo étnico racial (DIAS, 2005), (OLIVEIRA DE, 2013), (MAGALHÃES, 2016); sin que las categorias experiencia y agencia entretejan la comprensión de lo que emerge del trabajo de campo. Otros, como el realizado por Bidaseca (2005) muestra como la acción colectiva en el marco de un conflicto histórico, hace emerger nuevas subjetividades en el que se dislocan identidades, construyéndose políticamente frente a un orden que le pretende negar su existencia.

Sin que asuman el aparato categorial de los Feminismos del Sur, fueron de interés para este este estudio aquellos análisis que destacan el papel del movimiento social en la politización de la naturaleza, en la construcción de sujetos sociales, que establecen nuevas formas de solidaridad a través de sus actos políticos como el de Almeida (2013) o, la contribución específica realizada por el proyecto "Nueva Cartografía Social de la Amazonia” (MIQCB, 2005) por la metodologia utilizada, la preocupación por la interseccionalidad de género y por valorizar la contribución que hacen las quebradoras de coco a la producción de conocimientos, a partir de sus espacios específicos en la denominada "Región Ecológica dos Babaçuais".

Desde el punto de vista epistémico, reflexionar sobre este tema trajo a colación la comprensión conceptual realizada por los Feminismos del Sur 
sobre la agencia que es entendida en occidente como sinónimo de resistencia, de autonomía y subversión frente a las relaciones de dominación. Desde desde la influencia ejercida por autores como Foucault. Tanto Chandra Mohanti (2008) como Saba Mahmood (2006), realizan una crítica al entendimiento del feminismo occidental sobre la comprensión de las mujeres del tercer mundo como "otras" homogéneas, necesitadas de ser liberadas. En el caso de la segunda autora, quien estudió otras modalidades de agencia que se configuran en tradiciones no liberales como el movimiento femenino de las mezquitas en Egipto comprende la agencia como "capacidad para la acción creada y propiciada por relaciones concretas de subordinación históricamente configuradas”(MAHMOOD, 2006, p. 123), trata así, de superar los binarismos propios del feminismo occidental, aun cuando reconoce y se ve influenciada por los importantes aportes realizados por autoras como Judith Butler. A partir del entendimiento sobre el poder reconceptualiza la agencia " no sólo como un sinónimo de resistencia a las relaciones de dominación, más también como una capacidad para la acción propiciada por relaciones de subordinación específicas.'(MAHMOOD, 2006, p. 133).

En este artículo hacemos dejación de la comprensión de agencia usado por las tradiciones del feminismo y del pensamiento sociológico occidental para asumir la que emerge del feminismo decolonial, donde la agencia es analizada más en términos de intersubjetividad e interdependência permitiendo entender las variaciones en sus posicionalidades mediadas por la intercepcionalidad que imprimen factores como lo clasista, el género, lo racial, lo étnico, lo generacional. La agencia es entendida como capacidad para la acción, para la movilización y construcción de un movimiento social organizado con expresividad nacional, que crea modos efectivos y diversos de resistencia contenidas en sus prácticas sociales y en su mundo simbólico. Por otra parte, el concepto de experiencia ha sido central para el feminismo al dar significación política a lo personal, a la cotidianeidad específica de las relaciones sociales que marca la vida vivida por las mujeres en lo individual y lo colectivo. 
Siguiendo a Teresa de Lauretis la experiencia "es el proceso por el cual la subjetividade es constituída (...) A través de ese proceso una persona se coloca o es colocada en la realidad social"(LAURETIS, 1984, p.159) Si consideramos la diferencia como marca que imprime la vida vivida como mujeres en contextos de extrema vulnerabilidad, como es el caso de las mujeres que quiebran coco en el sudeste del Pará, entonces siguiendo a Avtar Brah la experiencia es el proceso de significación, una práctica de dar sentido, tanto simbólica como narrativamente. 'la experiencia no refleja una «realidad» ya dada, sino el efecto discursivo de los procesos que construyen lo que llamamos realidad"(BRAH, 2011, p.34)

La búsqueda de la agencia de las mujeres rurales construida en el marco de las tensiones que generan los conflictos socioambientales y la lucha por el território, requiere de suficiente empatía, para comprender en la opacidad sus experiencias, el como se construyen y constituyen en sujetos colectivos.

Se privilegiaron entrevistas narrativas como forma artesanal de comunicar experiencias subjetivas, teniendo en cuenta que su carácter desestructurado es una herramienta que permite comprender las experiencias y los contextos en que fueron construidas, así como los factores que producen los cambios y motivan las acciones. No se pretende con ellas la búsqueda de la verdad, pues, las narrativas no están abiertas a comprobación y no pueden ser juzgadas como verdaderas o falsas, expresan un punto de vista en determinado tiempo, espacio y contexto sociohistórico (Sandra JOVCHELOVICH y Martin BAUER, 2002), del cual emerge una historia particular que resulta de la interacción. Todo un proceso que articula momentos largos de conversaciones que desencadenan palabras que luego se tejen y encadenan para que sus voces no estuvieran ausentes en el texto que como autoras debíamos construir.

La pesquisa fue norteada alrededor de preguntas críticas que guiaron las entrevistas realizadas a las mujeres que conforman el movimiento de las quebradeiras de coco babaçu en el sudeste de Pará. Por su carácter narrativo las protagonistas realizan un recorrido por sus vidas, no sólo se destaca el 
momento actual y las motivaciones que llevan a las mujeres al diseño colectivo de estrategias como la conformación de grupos productivos y el asociarse en una cooperativa para comercializar las producciones, sino que ellas pasan revista a su historia de vida, la memoria sobre la movilidad espacial constante (forzada o voluntaria), de los puntos de llegada y los puntos de partida, de las violencias sufridas, de su poca o ninguna posibilidad de acceso a la escolarización; las angustias y sueños por el acceso a la tierra o las decisiones que hubieron de tomar en sus vidas. La diversidad de temáticas relacionadas a la salud, al medio ambiente, y a su condición y posición como mujeres; cuestiones que no solo permiten comprender sus experiencias individuales y colectivas, sino también la complejidad territorial del sudeste de Pará.

El trabajo de campo junto a las quebradoras de coco babaçu se realizó en varios municipios donde viven y realizan sus prácticas productivas; buscando respuestas a las interrogante que irian emergiendo: cómo informan la experiencia vivida y narrada por las mujeres las situaciones de conflictos socioambientales en el territorio, y sobre sus estrategias y acciones; cómo informan sobre los saberes movilizados en la defensa del territorio y de sus palmeras, sobre las prácticas de producción y comercialización; cómo informan sus cuerpos racializados sobre las violencias que articula esa relación entre capital y patriarcado, cómo se expresan sus agencias y los impactos que estas tienen sobre las posicionalidades de género en un contexto de colonialidad del poder y del saber9. Qué conocimientos emergen de sus luchas, como se construyen y cómo se refuerzan.

Concentrarnos en la experiencia y agencia de estas mujeres desde sus propios espacios de enunciación, es reconocer su lucha frente a los agentes de la dominación, entre ellos el estado, principal responsable en la "manutención del patriarcado" y la impunidad en que permanece la violencia ejercida contra las mujeres (Rita Laura SEGATO, 2011).

9 El términio se usa en el sentido dado por Anibal Quijano en Colonialidad del poder, Eurocentrismo y América Latina (2014) 


\section{Experiencia y agencia de las mujeres quebradoras de coco babaçu en el sudesde de Pará}

Este aspecto concentra la mirada en las narrativas. Ellas remiten (en un ir y venir del presente al passado), a los principales acontecimientos que marcan la vida personal o familiar, a las violencias que atraviesan sus prácticas cotidianas y también a la agencia, desde la génesis organizativa de la lucha y las movilizaciones sociales, para remarcar siempre lo que consideran las afirma desde el punto de vista político: la construcción del Movimiento Interestadual de las Mujeres Quebradoras de Coco Babaçu.

Quebrar coco es la principal actividad productiva generadora de renta, trasmitida de generación en generación que al ser narrada es resignificada, trayendo a colación escenas vividas en la cotidianeidad de sus prácticas y rituales.

Mi madre quebraba coco y trabajaba en la rosa, cuando creci yo también fui haciendo las mismas cosas, (...) quebrar coco. En la familia eramos ocho personas. Creci viendo a mi madre sustentarnos. Mi padre era castañero, él salía para la castaña castaña en noviembre y solo regresaba em marzo, la gente quedaba sin nada. Tenía que hacer algo para podernos mantener. Entonces iba a quebrar coco para vender y comprar alimentos, sustentar la casa hasta que él regresara en marzo10.

Desde su lugar de enuciación las quebradoras se remontan a la denominada por ellas como "tiempo de coco preso", expresión nativa, que recuerda episodios significativos relacionados al tiempo en que se veían privadas del coco babaçu, pues los propietarios de la tierra prohibían su entrada a los babuçuais. Ellos comenzaban a derrumbar las palmeras, a exigir trabajos a medias e, incluso a cambiar almendras recolectadas por alimentos

10 Entrevista realizada a Cledeneuza Maria Bizerra Oliveira, el 10/11, 2016. 
a los propietarios de la tierra. "O babaçu preso nos causó mucho dolor y sufrimiento, no era solo trabajar a medias, eran golpizas, eran las muertes" 11

La violencia emprendida, tomó el cuerpo de las mujeres como espacio objeto de dominación. Las amenazas de muerte, los asesinatos, golpizas y violaciones llevó a las mujeres a organizarse, primero en sindicatos rurales y luego en movimientos sociales12, una lucha por el libre acceso a babuçuais, por la defensa de su territorio simbólico, por su cultura extractiva. En esa trayectoria que moviliza la agencia, un lugar primigenio lo ocupan los Círculos Ecleciales de Base como espacio reflexivo y problematizador de la realidad.

En los círculo bíblico era donde la gente discutia la vida, el porqué de las cosas. El desarrollo que estaba aconteciendo, la situación que estabamos vivendo (...) allá en el Círculo Bíblico surgen las perguntas sobre la sociedad, sobre nuestra posición, y la gente iba a debatir, cada uno colocaba su opinión. Eso fue abriendo nuestra cabeza para la participación, la mia para donde yo estoy hoy.13

Luego vendría la necesidad de organizarse y los sindicatos eran el espacio adecuado para reivindicar derechos como trabajadoras rurales, sin embargo, el camino no sería facil, la cultura patriarcal silencia las voces femeninas y subordina sus demandas. Sobre este asunto, sus narrativas dan cuenta de un processo de lucha que las condujo a transgredir los sindicatos para reivindicar derechos como mujeres quebradoras de coco babaçu; en una linea temporal que nace en los años 80 y se consolida en la segunda mitad de los noventa con la aparición del Movimiento Interestadual.

Las mujeres comenzamos a participar de los sindicatos rurales, descubrimos que dentro de los sindicatos nuestros problemas eran colocados como informe,

\footnotetext{
11 Entrevista a Reymunda Celestina de Macena (a preta) el 18/10/ 2016.

${ }_{12}$ Uno de los movimentos sociales fue el Movimiento Interestadual de Quebradoras de Coco Babaçu (MIQCB) creado en 1995, luego de un largo proceso de problematización de sus realidades, de organización y articulación de grupos existentes.

13 Entrevista realizada a Cledeneuza Maria Bizerra Oliveira, el 10/11, 2016.
} 
el punto de pauta no era pauta, era informe; cuando estaban terminando la reunión decían las mujeres tienen un informe, ahí la gente no tenía oportunidades de desenvolverse dentro del sindicato. La gente no aceptó más ser sólo informe. Queriamos discutir nuestra situación también. Como los hombres discutian los problemas, las mujeres también tenían que discutir. Ahí las mujeres, de diferentes estados, Maranhão, Piaui, Tocantins, comenzamos a problematizar la situación, teníamos una actividad común que era quebrar coco, el período en que el marido estaba en la rosa la mujer sustentaba la casa quebrando coco. Nosotras somos sindicalizadas, mas, queríamos discutir nuestra situación separada de los hombres, (...) creamos un grupo, luego se tornó una asociación, ingresamos en 1998, nosotras éramos cuatro grupos en San Juan da Uruguaia, hacíamos discusiones, hoy somos ocho grupos.14

Desde prácticas cotidianas se recrea su mundo simbólico, que envuelve la recolección y quiebra del coco, el hacer carbón, producir el aceite, entre otras. Se quiebra coco con un hacha pequeña que llaman machado, sentadas en círculo, (una especie de relación horizontal, cara a cara) con las piernas abiertas, ritual acompañado de cantos. Cantar es un ritual que acompaña el trabajo colectivo, tiene múltiples sentidos "cuando salimos de casa dejamos la tristeza, nosotras, cantamos para no llorar.”15 Expresión metáforica salida del sufrimiento humano, una emoción que sale del dolor, de la violencia doméstica, que busca en el colectivo las redes de apoyo. Estos cantos también expresan una modalidad de agencia que contienen sueños, deseos, emociones; exigencias, por ejemplo: Xote das quebradeiras de coco16 cuyo contenido está dirigido a la preservación de las palmeras, a la exigencia del cumplimiento de la ley "babaçu livre", las palmeras como proveedora de fuente de alimentación, de reproducción de la vida y de renta. El xote es una herramienta de concientización y de educación ambiental hacia adentro del grupo en lo

\footnotetext{
14 Entrevista realizada a Cledeneuza Maria Bizerra Oliveira, el 10/11, 2016.

15 Frase de una de las mujeres quebradoras de coco (Blanca, 22/09/2016).

16 Puede ser leido en: http://lyricstranslate.com/pt-br/cantos-de-trabalho-xote-dasquebradeiras-de-coco-lyrics.html),
} 
cotidiano y hacia afuera como un grito que clama por la presevación de las palmeras y de las quebradoras.

Perturban este análisis, los conceptos tradicionales alineados a "la razón indolente" (SANTOS, 2003, p. 80) que separan cultura y naturaleza, y consideran la naturaleza como objeto a ser dominado y saqueado. Buscamos entonces, los sentidos que dan las quebradoras de coco a sus palmeras para encontrar otra matriz ontológica17 en las relaciones y representaciones que con y sobre las palmeras tienen estas mujeres. Relaciones de afectividad, árbol madre, que da y reproduce su vida; el espacio de las palmeras como territorio simbólico; la palmera como expresión de religiosidad "Santa Maria es nuestra compañera, Verdadera fuerza que proteje esta nación, Que fortalece nuestra lucha poco a poco, Es la mujer que quiebra el coco, la que pide su protección”.

La agencia de las quebradoras muestra una lucha por mantener su identidad colectiva como productoras, ejemplo de ello es la creación de la cooperativa, como espacio de comercialización de produtos como aceite, carbón y harina extraída del mesocarpo18.

Nuestra cooperativa oficializada en 2011, tiene importancia en la región, luchamos contra los preconceptos sobre las cooperativas, piensan que da pérdidas.Tenemos una discusión política sobre la responsabilidad de ser asociadaa. Creamos un fondo "Yo soy babaçu." Que es un fondo rotativo que al devolverse se presta a otra compañera. A un $3 \%$ anual de interés, se devuelve el $50 \%$ en los seis primeros meses y el resto en los seis segundos meses. Cada año salen 30 proyectos 5 para cada región) como prestamos rotativos a los grupos por un año. Es un fondo de asistencia a los gruposig.

\footnotetext{
17 Un interesante análisis referente al debate ontológico y sus diferentes corrientes realizan Daniel Ruiz Serna y Carlos Del Cairo en el texto "Los debates del giro ontológico en torno al naturalismo moderno"

18 Estas son las principales producciones comercializadas por la cooperativa de la Regional Pará. La cooperativa tiene carácter interestadual, su producción es diversa e incluye produtos de artesanía, jabones y también produtos usados en confitería y culinaria. Estas producciones están disponibles en el catalogo de produtos del MIQCB - http://www.miqcb.org/ y que muestra la variedade de usos que tiene la palmera.

19 Entrevista realizada a Cledeneuza Maria Bizerra Oliveira, el 10/11, 2016
} 
La responsabilidad respecto a la cooperativa ha posibilitado su presencia en ferias, marchas, congresos, reuniones, espacios que son aprovechados para la exposición y comercialización de los bienes producidos. Ello significa la movilidad espacial, el viajar a otros estados, incluso a la capital del país para demandar sus derechos como productoras y los derechos como mujeres:

No tenía voz, no podía hablar en público porque no era alfabetizada, era quebradora de coco y además soy una mujer negra (...), el movimiento nos hizo hablar, las mujeres nos estamos redescubriendo, ganamos confianza en nuestras propias fuerzas; nuestra participación en el movimento es nuestra mayor conquista, eso creo.20

Se hace referencia al Movimiento Interestadual de las Mujeres Quebradoras de Coco Babaçu21 (MIQCB), expresión política de la organización de mujeres que realizan esta actividad en los estados de Maranhão, Piaú, Tocantins y Pará, nacido en la primera mitad de la década de los noventa. Esta organización reivindica políticas públicas relacionadas a su condición y posición de género como mujeres rurales, desde la racialidad de sus cuerpos, entre ellas, la reforma agraria, y la sostenibilidad de los babuçuais como territorios simbólicos, el derecho a accesar libremente, entre otras. El MIQCB, articula redes de sociabilidad como asociaciones, clubes, comisiones, grupos de mujeres y cooperativas, constituyendo la representatibidad de las quebradoras como sujetos políticos. Su bandera política de lucha en la actualidad es la concresión práctica la Ley Babaçu Livre22.

20 Entrevista realizada a Joselice Rodrigues da Silva, 18/10/2016.

${ }_{21}$ El movimento (MIQCB) agrupa más de 2000 mujeres quebradoras de coco babaçu en unos 63 municipios del norte-nordeste de Brasil. El Rregional de Pará compreende los municípios de Brejo Grande do Araguaia, Palestina do Pará, São Domingos do Araguaia, São João do Araguaia.

22 Lei 231/2007. Lei do Babaçu Livre. O projeto, de autoria do deputado Domingos Dutra (PT/MA), proíbe a derrubada de palmeiras de babaçu nos estados do Maranhão, Piauí, Tocantins, Pará, Goiás e Mato Grosso, e cria regras para a exploração da espécie. 
En el sudeste del Pará el movimento de la quebradoras de coco lucha por que la ley "Babaçu Livre", sea una ley estatal, sólo está aprobada en el município en San Domingo y se exige poco por su cumplimiento. Esta ley federal otorga el derecho del libre acceso a los babuçais independentemente de quien sea el propietario de tierra; establece normas legítimas que garanticen la reproducción de práticas tradicionales, de protección de conocimientos y de formas de vida, considera a las palmeiras como bienes principales del suelo y prohibe su derrumbe. Para estas mujeres accesar a los babuçuais es ir más allá de garantizar la economia doméstica, es defender un modo equilibrado de ser y existir en un paisaje del que se consideran parte. Sin embargo, es a escala local donde debe concretarse esta ley y la mayoría de los dueños de la tierra tratan de evadir su cumplimiento. Situación que refuerza la agencia de las organización de las mujeres quebradoras del coco.

Realizamos movilizaciones, vamos a la cámara municipal. Queremos hacer valer esa ley, los dueños de la tierra están envenenando las palmeras, colocando cerca eléctrica para impedirnos entrar en el territorio, están contratando el coco entero para carbón, no quieren donar el coco para la gente, cuando denunciamos somos perseguidas, amenazan de muerte a nuestras compañeras, los cocos están quedando cada vez más lejos y la prefectura brinda poco apoyozs.

La violenccia contra las mujeres, es también una violencia que responsabiliza al Estado, es una cuestión de Estado (SEGATO, 2011) cuando no es capaz de hacer cumplir la legislación aprobada, cuando es indiferente ante un reclamo de apoyo, ante las amenazas y muertes de las mujeres.

Somos tan discriminadas que cuando juntamos el coco, muchas veces se estraga y no conseguimos apoyo de la prefectura para transportarlo (...) no vamos a pedir comida, pedimos sí, apoyo para producir (...). Nuestra lucha es

$<$ http://www2.camara.leg.br/atividade-legislativa/comissoes/comissoespermanentes/cmads/documentos/2007-08-09-comissao-aprova-lei-do-babacu-livre> 23 Entrevista realizada a Crise Santos, diretora de Consejo Fiscal da cooperativa y coordenadora de uno de los grupos (18/10/2016. 
por el babaçu libre, es una cuestión de todas nosotras, queremos a las mujeres y a las palmeras vivas24.

Este discurso, si bien, por una parte, nos habla de negociaciones, de exigencias, de utopías, también expresa las condiciones de vulnerabilidad en que se encuentran las mujeres y sus palmeras. Entre las mujeres y entre las mujeres y las palmeras de Coco Babaçu existe una interdependencia y una ecodependencia puesta en juego por los conflictos socioambientales que definen la expansión del capital en el sudeste del Pará; que siguiendo a (Amaia PEREZ, 2013) se trata de un conflicto de lógicas: de la lógica de la acumulación y la lógica de la sostenibilidad de la vida. Y es esa segunda lógica la que nutre las experiencias de la mujeres que quiebran coco en el sudeste del Pará.

Uno de los espacios, más valorizados por las mujeres entrevistadas fue el logrado en el marco del Proyecto "Mapeamento Social como Instrumento de Gestão Territorial contra o Desmatamento e a Devastação: Processos de Capacitação de Povos e Comunidades Tradicionais" (Rita PEREIRA, 2015), considerado como medio de dar visibilidad a sus luchas, sus prácticas sociales y productivas, como medio de denuncia de los conflictos que envuelven sus vidas y además, como importante instrumento en el camino del reconocimiento de su existencia y la concreción de las leyes "Babaçu livre" y la ley que da protección a los balbuçuais.

Las narrativas dan cuenta del protagonismo asumido en el mapeamiento participativo, elaborando sus propios croquis y leyendas, brindando informaciones precisas sobre los conflitos sociaoambientales, los espacios de devastación, espacios de trabajos colectivo e infraestructuras conquistadas. Una espécie de "Ecologia de Saberes" (SANTOS, 2011) en que saberes historicamente subordinados dialogan de manera horizontal con los saberes académicos legitimados institucionalmente, experiencia compartida de la que emerge el mapa social. El relatorio del mencionado proyecto registra 
momentos en que las quebradoras participantes realizan devolución del mapa construido al grupo mayor:

Aqui en ese mapa nosotras nos localizamos, en cuatro municipio - en que la gente trabaja - São João, São Domingo, Brejo Grande e Palestina, y tambien en Nova Ipixuna. Y, ahí entonces, la gente fue hablando de las amenazas que tienen (...). São João, Brejo Grande e Palestina sufren una gran ameaza con la cuestión de la hidrelétrica. Para todos es el derrumbe de las palmeras. Ven el envenenamento de las pindovas. Ven la quema del coco entero. Ahí, aquí lo arrastran con el tractor, que pasa así, limpiando y deja las palmeras en pie, más cuando viene el viento - ahí las palmeras están con las raíces descubiertas por el tractor que cabó - y caen las palmeras. Y la siderúrgica, con el consumo de carbón (... ) ella tira todo para quemar. Son las amenazas que nosotras sufrimos. (Palabras de Cleudinelsa, en Relatorio de pesquisa, 2015 p.14)

La narrativa de las quebradoras permitió tejer en red la diversidad de voces que registran los conflictos en lo cotidiano con un poder que desterritorializa y desposeciona del uso de los bienes tradicionales: la devastación, el envenenamento, el arrendamiento de los cocales para la producción de carbón, entre otras, convierten al territorio simbólico en un campo de disputa, pero también de agencias. Como expresa la coordenadora de la Cooperativa:

Estamos produciendo y mostrando para el Brasil nuestra capacidad y tambien teniendo corage de mostrar nuestra identidad, quien tenia verguenza de decir que era quebradora, hija de quebradora. La gente hoy sabe que estamos formando parte de esta historia, de esa nueva construcción luchando por la transformación, que esta sociedad necesita25

\section{CONCLUSIONES}

25 Entrevista a Cledeneuza Maria Bizerra Oliveira el 15/12/2016. 
Comprender la experiencia y la agencia de las Mujeres Quebradoras de Coco Babaçu en el sudeste del Pará significó seguir la ruta de sus trayectorias en cada narrativa que se movían de manera artesanal entre lo individual y lo colectivo, entrecruzadas con el contexto situacional. A través del contenido de lo narrado y lo vivido apreciamos las variadas formas en que las quebradoras de coco expresan su agencia, cuya máxima expresión es el movimiento social que las concreta como sujetas políticas: MIQCB. Todo ello, en condiciones de extrema vulnerabilidad impuesta por el desequilibrio en las relaciones de poder y de las lógicas en que ellas y el capital se relacionan con el territorio y la naturaleza. Si para ellas es modo y fuente de vida, para el capital se torna espacio objeto apropriado y mercantilizado.

Las experiencias de las Mujeres Quebradoras de Coco Babaçu, están relacionadas a la lucha por la vida de las palmeras que por simbiosis, tal como ellas lo comprenden es luchar por sus propias vidas, ligada a un territorio simbólico del que forman parte y al que defienden, es una lucha por la sobrevivencia de lo que las define como extractivistas, es una lucha por el derecho a ser y existir como mujeres, derecho que también le es trasladado a sus palmeras, consideradas en sus ritos como una madre que da vida.

Las prácticas socioproductivas, culturales y simbólicas desarrolladas por estas mujeres las vinculan al uso de los bienes que brinda el bioma amazónico y por tanto, están interesadas en su gestión sostenible. Las mujeres tienen un conocimiento que es diferenciado, relacionados con las maneras con que sus prácticas cotidianas las ha vinculado al cuidado y sostenibilidad de la vida.

Espacios de accionar colectivo, como el quebrar coco o su organización en una cooperativa, más más allá de los objetivos de generación de renta, son espacios de participación y gestión democrática, de solidaridad, autonomía y de problematización de sus condiciones y posicionalidades como mujeres.

La lucha por las palmeras muestra que las mujeres están andando, una agencia por mantener una experiencia de vida como pueblo tradicional, ligada a un territorio simbólico, en el que se consideran guardianas de la vida y la naturaleza, es una lucha por su sobrevivencia como extractivistas, por el 
derecho a ser y existir como mujeres, derecho que también le es trasladado a sus palmeras.

\section{Referencias}

ALMEIDA, A.W. B. de. Guerra ecológica nos babaçuais: o processo de devastação dos palmeirais, a elevação do preço de commodities e o aquecimento do mercado de terras na Amazônia. San Luis: MIQCB/Balaios Typ. 2005.

ALMEIDA, A. W. B de; "Nova Cartografia Social: territorialidades específicas e politização da consciência das fronteiras". In: ALMEIDA, A. W. B de; ALMEIDA E. F. de (Orgs.). Povos e comunidades tradicionais. Nova cartografia social. Manaus: UEA Edições, 2013.

BIDASECA, K. "Negadas a la existencia y condenadas a la desaparición un estudio acerca de las luchas de las mujeres rurales en Argentina y Brasil desde la perspectiva de género". Jóvenes [on line]. Buenos Aires, 2005, no. 6, p. 355-417.Disponible en:

<http://bibliotecavirtual.clacso.org.ar/ar/libros/ruralidad/Bidaseca.pdf> Acceso el: 06 set.2018.

BRAH Avtar. Cartografías de la diáspora. Identidades en cuestión. Madrid: Traficantes de Sueños, 2011.

COELHO T. "Projeto Grande Carajás: Trinta anos de desenvolvimento frustrado”. In: TROCADE Ch., ZONTA M. (Org.). A questão mineral no Brasil - Vol 1. Marabá: Iguana Editorial, 2015. p. 27-158.

DIAS, Luciene de Oliveira. Mulheres de fibra: As estratégias das quebradeiras de coco no Tocantins como marco empírico para o desenvolvimento sustentável. 2005. Programa de Mestrado em Ciências do 
Ambiente. Coordenação de Pós-Graduação e Pesquisa - Fundação Universidade Federal do Tocantins. Palmas,Tocantins, Brasil.

FOUCAULT, M. Nascimento da biopolítica: Curso dado no Collège de France (1978-1979). São Paulo: Martins Fontes, 2008.

HARVEY, D. “El "nuevo” imperialismo: acumulación por desposesión”. Buenos Aires: CLACSO, 2005. Disponible en:

<http://biblioteca.clacso.org.ar/clacso/se/20130702120830/harvey.pdf> Acceso el: 22 out. 2017.

JOVCHELOVICH Sandra, BAUER W Martin. "Entrevista Narrativa". In: BAUER, Martin W; GASKELL George. (Eds.). Pesquisa qualitativa com texto, imagem e som: um manual prático. Petrópolis: Vozes, 2002. p. 90-113.

LAURETIS Teresa de. Alice doesn 't. Indiana: University Press, 1984.

LEI 231/2007. Lei do Babaçu Livre. Projeto. Disponible en:

<http://www2.camara.leg.br/atividade-legislativa/comissoes/comissoespermanentes/cmads/documentos/2007-08-09-comissao-aprova-lei-do-babaculivre $>$. Acceso el : 22 out.2016.

MAGALHÃES Ana Carolina. Reflexões e contribuições para a etnografia das práticas cotidianas de resistência das quebradeiras de coco babaçu de Codó. 2016. Tese (Mestrado em Cartografia Social e Política da Amazônia) Programa de pós-graduação em Cartografia Social e Política Da AmazôniaPPGCSPA, Centro De Ciências Sociais Aplicadas da Universidade Estadual do Maranhão (UEMA), São Luís-MA, Brasil.

MAHMOOD, Saba. "Teoría feminista, Agência e sujeto liberatório: algumas reflexôes sobre o revivalismo islâmico no Egipto". In: Etnográfica [online Standford]. vol.10, n.1, p.121-158, maio. 2006. 
MARINHO, Josete. Uma palmeira em muitos termos: a terminologia da cultura agroextrativista, industrial e comercial do coco babaçu. 2008. Tese (Doutorado em Linguística) - Programa de Posgraduação em Linguística do Departamento de lenguas Vernáculas da Universidade Federal de Ceara, Fortaleza-CE, Brasil

MEDEIROS DA SILVA, Nirson (2008), Quebradeiras de coco babaçu do Araguaia-tocantins: estratégias locales de reprodução social e cultural. Hiléia - Revista do Direito Ambiental da Amazônia. Manaos, 2008 [on-line]. n. 11 jul/ dez. p.74-115. Disponible en: www.pos.uea.edu.br/direitoambiental/ Acceso el: 01 jan. 2017.

MIQCB. Nova cartografía social da Amazonia. Série: Movimentos sociais, identidade coletiva e conflitos. MIQCB: São Luís, 2005.

MIQCB. "Projeto Nova Cartografia Social da Amazônia Série: Movimentos sociais, identidade coletiva e conflitos”. FASCÍCULO 5. Quebradeiras de coco babaçu do Pará. MIQCB: São Luís, 2013.

MIQCB. Catalogo de produtos de $M I Q C B$. Disponible en: $<$ http://www.miqcb.org/>

Acceso el: 18 ago. 2018.

MOHANTY, Chandra "Bajo los ojos de occidente. Academia feminista y discurso colonial”. In SUÁREZ Liliana, HERNÁNDEZ Rosalva Aída (eds.). Descolonizando el Feminismo: Teorías y Prácticas desde los Márgenes. Madrid: Editorial Cátedra, 2008. p.113-16.1

OLIVEIRA Viviane de. Mulheres do Babaçu: género, maternalismo e movimento sociais do Maranhão. 2013. Tese (doutorado em História) Programa de Pós-Graduação em História, Instituto de Ciências Humanas e Filosofia da Universidade Federal Fluminense, Niterói, RJ, Brasil. 
PEREZ, Amaia O. "La sostenibilidad de la vida en el centro. ¿y eso que significa?" In - IV JORNADAS ECONOMÍA FEMINISTA. Universidad Complutense de Madrid, 2013. Disponible en:

$<$ http://pendientedemigracion.ucm.es/info/ec/jec10/ponencias/512perezorozco .pdf > Acceso em: 11 out. 2017.

PEREIRA DE COSTA Rita. Mapeamento Social como Instrumento de Gestão Territorial contra o Desmatamento e a Devastação: Processos de Capacitação de Povos e Comunidades Tradicionais. Relatório (Material digitalizado). Universidad Federal del Sur y Sudeste de Pará, Marabá, Pará. 2015. 93 f.

PINASSI M., GOMES DA CRUZ R. "A mineração e a lógica da produção destrutiva na Amazônia". In: TROCADE, Ch.; ZANON, M.; VIEIRIA J. (Org.). Elementos constitutivos do MAM. Marabá: Iguana Editorial, 2015. p. 21-49

QUIJANO, A. Colonialidad del poder, Eurocentrismo y América Latina. In: QUIJANO A. Cuestiones y Horizontes. De la dependencia HistóricoEstructural a la Colonialidad/Descolonialidad del poder. Buenos Aires: CLACSO. Colección Antologías, 2014. p. 777-832.

RUIZ Daniel, DEL CAIRO Carlos . (2016), Los debates del giro ontológico en torno al naturalismo moderno. In: Rev. Estudios Sociales. [online]. Bogotá, 2016, n. 55 ene/mar p. 193-204. Disponible en: $<$ http://dx.doi.org/10.7440/res55.2016.13>. Acceso 23 nov.2016.

SANTOS, B. S. de. Critica de la razón indolente contra el desperdicio de la experiencia. Bilbao:V.1. Declée DeBrower, S,A, 2003. 
SANTOS, B. S. de. Epistemologías del Sur. In: Revista Internacional de Filosofía Iberoamericana y Teoría Social, Maracaibo, Año 16. n. 54, p.17-39, Jul/Sep. 2011.

SEGATO, R.. "Femi-geno-cidio como crimen en el fuero internacional de los Derechos Humanos: el derecho a nombrar el sufrimiento en el derecho". In: FREGOSO, Rosa Linda; BEJARANO Cyntia. (Org.). Feminicidio en América Latina. UNAM-CIIECH: México, DF, 2011. p. 1-30.

SHIVA Vandana MIES Maria "Ecofeminismo. Teoría, Crítica y Perspectivas". Barcelona. Icaria Editorial. 2013 (PREFACIO A LA NUEVA EDICIÓN), Disponible en: <http://www.icariaeditorial.com/pdf_libros/ecofeminismo.pdf $>$ Acceso el: 21 nov. 2017.

XOTE DAS QUEBRADEIRAS DE COCO. Disponible en: $<$ http://lyricstranslate.com/pt-br/cantos-de-trabalho-xote-das-quebradeirasde-coco-lyrics.html>. Acceso el: 21 nov. 2017.

Recebido em agosto de 2019. Aprovado em dezembro de 2019. 